\title{
Effects of menopause and obesity on lipid profiles in middle-aged Taiwanese women: the Chin-Shan Community Cardiovascular Cohort Study
}

\author{
Pao-Ling Torng a, Ta-Chen Su ${ }^{\text {b }}$, Fung C. Sung ${ }^{\mathrm{c}}$, Kuo-Liong Chien ${ }^{\mathrm{b}}$, \\ Su-Cheng Huang a, Song-Nan Chow ${ }^{a}$, Yuan-Teh Lee ${ }^{\mathrm{b}, *}$ \\ a Department of Obstetric and Gynecology, National Taiwan University College of Medicine, Taipei, Taiwan, ROC \\ ${ }^{\mathrm{b}}$ Department of Internal Medicine, National Taiwan University College of Medicine, No 7 Chungshan South Rd., Taipei 10020, Taiwan, ROC \\ ${ }^{\mathrm{c}}$ Institute of Environmental Health, National Taiwan University College of Public Health, Taipei, Taiwan, ROC
}

Received 19 March 1999; received in revised form 28 January 2000; accepted 14 February 2000

\begin{abstract}
In this cross-sectional study, we examined the associations between lipid profiles and menopausal status, age, and obesity in Taiwanese women. The study population, established in 1990-91, consisted of 671 premenopausal and 872 postmenopausal women from the Chin-Shan Community Cardiovascular Cohort (CCCC). The associations of age, body mass index (BMI), and menopausal status with serum levels of total cholesterol (TC), low-density lipoprotein cholesterol (LDL-C), high-density lipoprotein cholesterol (HDL-C), triglycerides (TG), apoproteins (Apo) A-1 and B, and lipoprotein (a) [Lp (a)] were evaluated. The results showed that menopause was associated with significant increases in TC, LDL-C, TG, and Apo B levels (all $P<0.001$ ). Total cholesterol, LDL-C, TG, and Apo B levels increased consistently with BMI in middle-aged women, regardless of menopausal status. Among women aged 45-49, menopausal women had significantly higher levels of TC and LDL-C than premenopausal women $(P<0.01)$. However, TG and Apo B levels were higher in postmenopausal than in premenopausal women aged 50-54 years $(P<0.05)$. Standardized regression analyses showed all lipid variables, except those of Apo A1 and Lp (a) before menopause and TC, LDL-C, and Lp (a) after menopause, were significantly associated with BMI (all $P<0.01$ ). We conclude serum lipid levels in Taiwanese women are no more strongly associated with menopause and BMI than with age. (C) 2000 Elsevier Science Ireland Ltd. All rights reserved.
\end{abstract}

Keywords: Menopause; Obesity; Lipids; Lipoproteins; Apoproteins; Taiwanese women

\section{Introduction}

The Framingham study reported that women usually lag men by 10 years in the development of coronary heart diseases (CHD) [1]. This difference is generally

\footnotetext{
Abbreviations: Apo A1, apoprotein A1; Apo B, apoprotein B; BMI, body mass index; CCCC, Chin-Shan community cardiovascular cohort; HDL-C, high-density lipoprotein cholesterol; LDL-C, low-density lipoprotein cholesterol; Lp (a), lipoprotein (a); TC, total cholesterol; TG, triglyceride.

* Corresponding author. Tel.: + 886-2-23562000; fax: + 886-223217522/23826649.

E-mail address: ytlee@ha.mc.ntu.edu.tw (Y.-T. Lee).
}

lost in women after menopause; the incidence of coronary events in menopausal women is quadruple that of premenopausal women of the same age [1]. Numerous authors consider menopause as a risk factor for CHD [1-3]. In contrast, Casiglia et al. [4] reported menopause did not influence cardiovascular disease risk in a 16-year longitudinal study.

Menopause is reported to be associated with increased serum levels of total cholesterol (TC), low-density lipoprotein cholesterol (LDL-C), triglycerides (TG), apoprotein B (Apo B) [5-10], and lipoprotein (Lp)(a) $[5,6]$, and decreased levels of apoprotein A1 (Apo A1) [5] and high-density lipoprotein cholesterol (HDL-C) $[5,7,9]$. Several epidemiological studies have reported 
that high serum TC [2,11,14], TG [2], LDL-C [2], lipoprotein (a) [Lp (a)] [14], and Apo B [13] and low HDL-C $[2,12,14]$ levels are risk factors for cardiovascular disease (CVD) mortality in females.

Obesity is also considered an independent risk factor for CVD [15] and the increased risk extends to even mildly or moderately overweight women [16]. Prospective studies have shown a strong correlation between $\mathrm{CHD}$ and the amount of abdominal visceral adipose tissue and LDL-C/HDL-C and Apo A1/Apo B ratios $[17,18]$.

Previous studies delineating the relationship between menopause and serum lipid levels were usually based on small sample sizes, with a limited number of studies depicting the relationship of menopause with Apo A1, Apo B, and Lp (a) concentrations. Additionally, few studies have included Asian women in their cohorts; the study by Lyu et al., comparing Taipei and Framingham women, was based only on Taipei government employees [8]. The confounding effect of obesity has rarely been incorporated in comparisons of lipid profiles between menopausal stages. Of importance is that CVD prevalence in premenopausal Taiwanese women is lower than men, but this pattern is reversed for postmneopausal women. The hypothesis is significant changes in lipid profiles may occur in postmenopausal Taiwanese women [19].

The Chin-Shan Community Cardiovascular Cohort (CCCC) study, established in 1990-91, is a communitybased investigation of CVD in adults consisting of 1899 men and 1703 women aged 35 and above. The purpose of the present study was to examine the relationships between serum lipid profiles and menopause, obesity, and age among women in Taiwan.

\section{Patients and methods}

\subsection{Study population}

Chin-Shan is a suburban community located 20 miles outside metropolitan Taipei. The mortality pattern in Chin-Shan was similar to that of the general Taiwanese population from 1980 to 1994 [20]. Women undergoing hormone replacement therapy prior to, or during the CCCC project study, were excluded from this report. This study was based on the baseline data on the year 1990-91. Women with a history of diabetes, fasting sugar >140 mg, hysterectomy, oophorectomy, oral contraceptive pill use, or menopause before the age of 45 years were excluded from the current study. Only subjects with secondary amenorrhea of at least 1 year were defined as menopausal. Women who still experienced menstruation 3-11 months prior to this study were also excluded since it was uncertain whether they were at the stage of menopause.

\subsection{Data collection and assays}

A study clinic was set up at the Chin-Shan Community Health Center (CCHC). It consisted of ten senior residents and cardiologists (TCS, KLC, YTL) in conjunction with the surveillance group of 20 senior medical students, two assistant nurses, local practitioners, and CCHC officers. Trained medical students canvassed door-to-door with the assistance of community leaders to extend invitations for the baseline survey. The CCC cohort consisted of 4350 adult aged 35 and above. Among 3602 respondents (82.8\%) in the baseline survey of the cohort, $47.3 \%(n=1703)$ were men and $52.7 \%(n=1899)$ were women.

Non-respondents included 95 (2.2\%) refusals and 652 $(15.0 \%)$ individuals who could not be reached. Information collected included sociodemographic characteristics, life style factors, dietary characteristics, personal and family histories of disease, and hospitalization records. Written consent was obtained during the faceto-face questionnaire interview, and physicians later conducted physical examinations and laboratory tests on participants invited to the clinic. Specimens for blood analyses were also collected at the clinic.

All venous blood samples were taken after a $10-\mathrm{h}$ overnight fast, immediately refrigerated, and transported to the National Taiwan University Hospital within $6 \mathrm{~h}$. Assay of serum TC and TG levels were performed within $24 \mathrm{~h}$. Serum samples were then stored at $-70^{\circ} \mathrm{C}$ for batch assay of LDL-C, HDL-C, Apo A1, Apo B, and Lp (a) as previously described [21,22]. These determinations were usually completed within 2 weeks. Few specimens were repeated for the determinations of HDL-C, LDL-C, Apo A1 and Apo B after storage of about 9 to 12 months and of $\mathrm{Lp} \mathrm{(a)} \mathrm{after}$ storage of about 1-2 years. Standard enzymatic methods for serum TC and TG were used (Merck 14354 and 14366, Germany). The HDL-C concentration in the supernatant was measured after precipitation with magnesium chloride phosphotungstate reagents (Merck 14993). The concentration of LDL-C was calculated as 'total cholesterol - cholesterol in the supernatant', and LDL-C was precipitated by heparin-citrate reagent (Merck 14992) [23]. Apo A1 and Apo B concentrations were measured by turbidimetric immunoassay using commercial kits (Sigma, USA). Lp(a) was measured with an enzyme-linked immunosorbent assay kit (Organon, USA), regardless of isoform. The between and within-batch coefficients of variation for each tests are $<5 \%$. Two controls at low and high concentrations were within two standard deviations.

$\mathrm{BMI}$, an indicator related to the amount of visceral fat [24], was used as a measure of obesity and was calculated as body weight in $\mathrm{kg}$ divided by height in $\mathrm{m}^{2}$; these parameters were measured at the time of blood sampling. A BMI of $26 \mathrm{~kg} / \mathrm{m}^{2}$ or greater was considered 
an indication of obesity, based on a Chinese population study in Taiwan [25].

\subsection{Statistical analyses}

We attempted to isolate the effects of menopause by incorporating the effects of age and obesity in the statistical analyses. We first compared the overall average level of each lipid by menopausal status, and the average level of each lipid for every 5-year-age band from 35-39 through 55-59 years old for premenopausal women and from 45-49 through 60 and above for postmenopausal women. Pearson correlation analysis was performed to measure the relationships between the age bands and average lipid levels. We also compared the average menopause-specific lipid profiles for women aged 45-49 and those aged 50-54 years.

Lipid profiles with respect to obesity (BMI $<26$ vs. $\geq 26 \mathrm{~kg} / \mathrm{m}^{2}$ ), were further categorized into five groups (BMI $<21,21-23,23-25,25-27$, and $\geq 27 \mathrm{~kg} / \mathrm{m}^{2}$ ) for women aged between 45 and 54 years. A multiple linear regression analysis was then used to examine the relationships between age, BMI, and each lipid profile for premenopausal and postmenopausal women. All statistical analyses were performed with SAS statistical software (Version 6.12, SAS Institute, Cary NC, USA). $P$ values below 0.05 were considered statistically significant.

\section{Results}

One thousand five hundred and forty three $(81.3 \%)$ of the 1899 respondents met the entry criteria for this study, including 671 premenopausal and 872 postmenopausal women. The baseline average age (standard deviation) for women included in the analysis was
52.7 (12.2) years (range, 35-96 years). The mean age was 42.7 (5.8) years for premenopausal women and 61.2 (9.5) years for postmenopausal women. The mean age at the onset of menopause was 49.7 (4.3) years, and the average duration since menopause was 12.9 (9.1) years.

Data analyses revealed no significant differences in the effects of smoking or alcohol consumption on lipid profiles between premenopausal and postmenopausal women (data not shown). Only $4 \%$ of women were smokers, and few women drank regularly. Table 1 depicts the differences in lipid profiles between premenopausal and postmenopausal women. There was no difference in average BMI between premenopausal and postmenopausal women. However, the levels of TC, TG, LDL-C, and Apo B, but not HDL-C, Apo A1, or Lp (a), were significantly higher in postmenopausal women. The Apo B/Apo A1 and the TC/HDL-C ratio was thus higher in postmenopausal than in premenopausal women. However, the median value of $\mathrm{Lp}$ (a) was higher in postmenopausal women $(9.7 \mathrm{mg} / \mathrm{dl})$ than in premenopausal women $(8.3 \mathrm{mg} / \mathrm{dl})$. When CHD risk classifications were selected, significantly greater proportions of the premenopausal group had desirable levels of TC ( $<200 \mathrm{mg} / \mathrm{dl} ; 68.6$ vs $41.0 \%)$ and LDL-C $(<130 \mathrm{mg} / \mathrm{dl} ; 58.9$ vs $33.0 \%)$ than did the postmenopausal group (both, $P<0.001$ ). Postmenopausal women had a higher percentage of low HDL-C levels $(<35 \mathrm{mg} / \mathrm{dl})$ than premenopausal women (11.6 vs $7.7 \%, P<0.05)$ had.

Fig. 1 shows the serum lipid levels by age and menopausal status. TC, LDL-C, and TG tended to rise as age increased, with significant increases only for TC and LDL-C in premenopausal women $(P<0.05)$. However, premenopausal women had lower levels of TC, LDL-C, and TG than postmenopausal women at every age band between 45 and 59 years. The largest gap between the two groups $(20 \mathrm{mg} / \mathrm{dl}$ for TC or LDL-C)

Table 1

Serum lipid concentrations by menopausal status among women in the Chin-Shan Community Cardiovascular Cohort Study

\begin{tabular}{|c|c|c|c|}
\hline & Premenopause $(n=671)$ & Postmenopause $(n=872)$ & $P^{\mathrm{b}}$ \\
\hline Age (years) & $42.7 \pm 5.8$ & $61.2 \pm 9.5$ & $<0.001$ \\
\hline Body height $(\mathrm{cm})$ & $154.7 \pm 5.4$ & $152.0 \pm 5.7$ & 0.16 \\
\hline BMI $\left(\mathrm{kg} / \mathrm{m}^{2}\right)$ & $23.8 \pm 3.4$ & $23.8 \pm 3.5$ & 0.20 \\
\hline $\mathrm{TC}(\mathrm{mg} / \mathrm{dl})$ & $186.6 \pm 40.0$ & $211.7 \pm 45.3$ & $<0.001$ \\
\hline TG $(\mathrm{mg} / \mathrm{dl})$ & $98.7 \pm 67.6$ & $125.6 \pm 79.9$ & $<0.001$ \\
\hline TC/HDL-C & $3.92 \pm 1.21$ & $4.59 \pm 1.43$ & $<0.001$ \\
\hline Apo A1 (g/l) & $1.30 \pm 0.23$ & $1.29 \pm 0.23$ & 0.19 \\
\hline Apo B (g/l) & $0.83 \pm 0.26$ & $0.99 \pm 0.29$ & $<0.001$ \\
\hline Apo B/Apo A1 & $0.65 \pm 0.22$ & $0.78 \pm 0.24$ & $<0.001$ \\
\hline Lp (a) (mg/dl) (median) & $13.8 \pm 15.9(8.3)$ & $14.8 \pm 15.9(9.7)$ & 0.20 \\
\hline
\end{tabular}

\footnotetext{
${ }^{\text {a }}$ Data are expressed as the mean \pm standard deviation (and median values for Lp (a)).
}

${ }^{\mathrm{b}} P, P$-value for difference between pre- and post-menopausal groups ( $t$-test) 

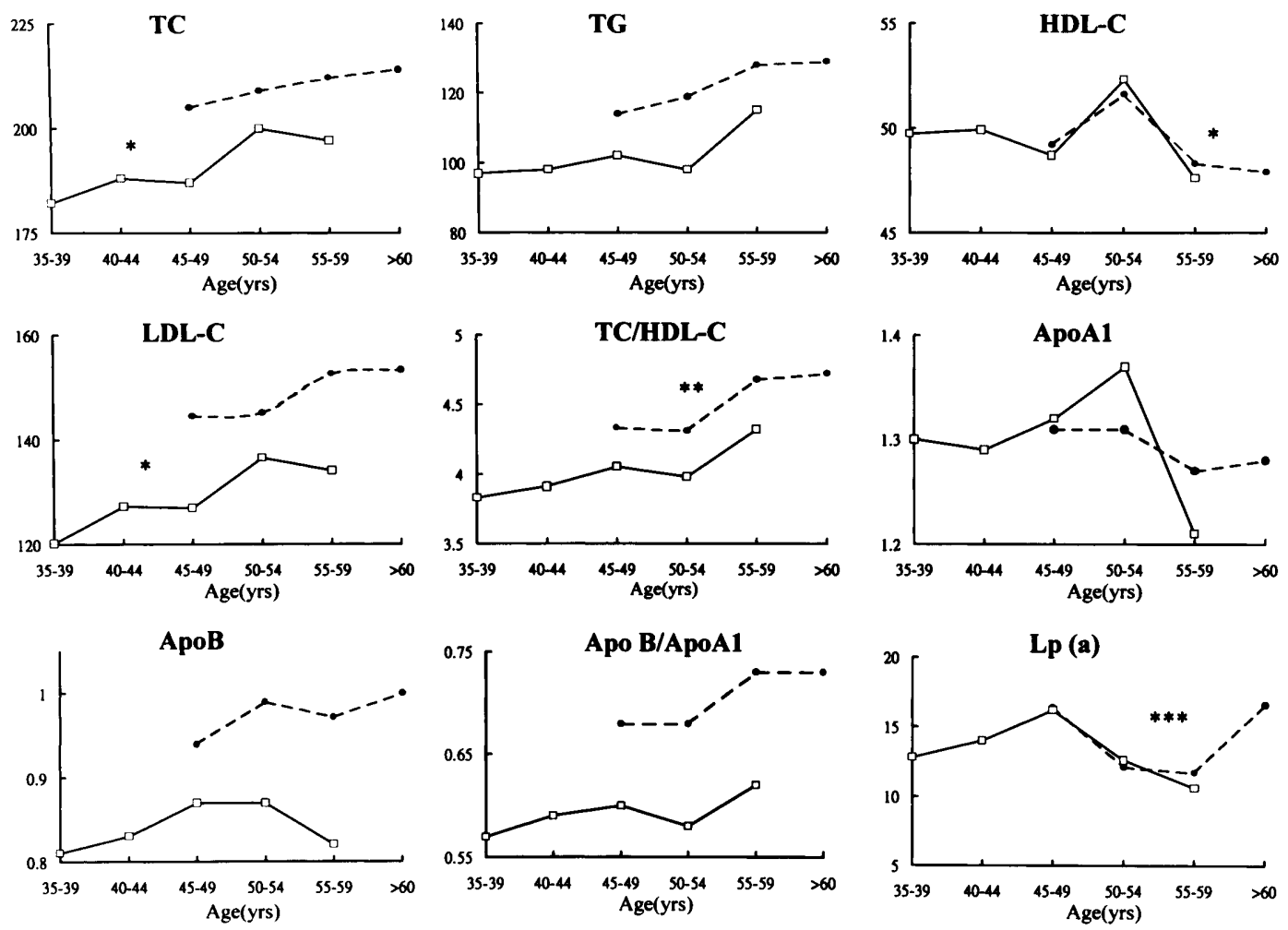

Fig. 1. Serum lipid concentrations ( $\mathrm{mg} / \mathrm{dl}$, and $\mathrm{g} / \mathrm{l}$ for apoproteins) according to 5-year age bands in premenopausal (---) and postmenopausal (...) women Chin-Shan Community, Taiwan. In the premenopausal group there were 266, 184, 147, 56, and 18 women in the 35-39, 40-44, $45-49,50-54$, and $55+$-year age bands, respectively; in the postmenopausal group there were $63,162,159$, and 461 women in the 45-49, 50-54, $55-59$, and $60+$-year age bands, respectively.*, $P<0.05$; **, $P<0.01 ; * *, P<0.001$ (regression of lipid on age).

was in the 45-49 year age band. The change in HDL-C concentration was associated with age but not menopause. In both groups, the highest average HDL-C and Apo A1 concentrations were found in the age band from 50 to 54 years. Average Lp (a) concentration peaked at 45-49 years of age in both groups. The average HDL-C, Apo A1, and Lp (a) levels tended to drop in the older age bands, but only the decrease in HDL-C was significant $(P<0.05)$. Among postmenopausal women, the Lp (a) level increased again after the ages of 55-59.

Table 2 compares menopausal-specific average levels of serum lipid among women of two age groups, 45-49 and 50-54 years. Again, postmenopausal women had significantly higher TC and LDL-C levels than premenopausal women at younger (both $P<$ $0.01)$ but not older ages. In the older group, TG and Apo B levels were significantly higher in postmenopausal women (both $P<0.05$ ). The postmenopausal women also had a higher average Apo $\mathrm{B} /$ ApoA1 ratio $(P<0.05$ in the older group) and higher median values of $\mathrm{Lp}$ (a).

Fig. 2 shows that, with the exception of HDL-C, Apo A1, and Lp (a) concentrations, the levels of serum lipids and Apo B were elevated in postmenopausal women, compared with premenopausal women, regardless of their obesity status. These dif- ferences were greater in non-obese than in obese women.

Fig. 3 shows the lipid profile changes with BMI and menopausal status for women 45-54 years old. The average LDL-C level in premenopausal women increased steadily from 120 to $146 \mathrm{mg} / \mathrm{dl}$ when BMI was stratified into levels of $<21,21-23,23-25,25-$ 27 , and $\geq 27 \mathrm{~kg} / \mathrm{m}^{2}$. The average TC value in premenopausal women also increased as BMI increased, but with a weaker trend. TG and Apo B levels were also elevated in postmenopausal women, except for TG in women with $\mathrm{BMI} \geq 27 \mathrm{~kg} / \mathrm{m}^{2}$.

Standardized regression analyses by age and BMI shown in Table 3 suggest that age had a positive correlation with premenopausal TC, LDL-C levels and postmenopausal Apo B/Apo A1 ratio $(P<0.05)$, and a negative correlation with postmenopausal HDL-C $(P<0.05)$. BMI was positively correlated with TG and Apo B concentration, as well as the TC/HDL-C and the Apo B/Apo A1 ratio, and negatively correlated with HDL-C concentration in both pre- and postmenopausal women (all $P<0.001$ ). Significant trends between BMI and TC and LDL-C were found only in premenopausal women (both $P<$ 0.001 ), and between BMI and Apo A1 in only postmenopausal women $(P<0.01)$. 
Table 2

Menopause-specific average serum lipid concentrations of women aged 45-49 and 50-54 years in the Chin-Shan Community Cardiovascular Cohort Study

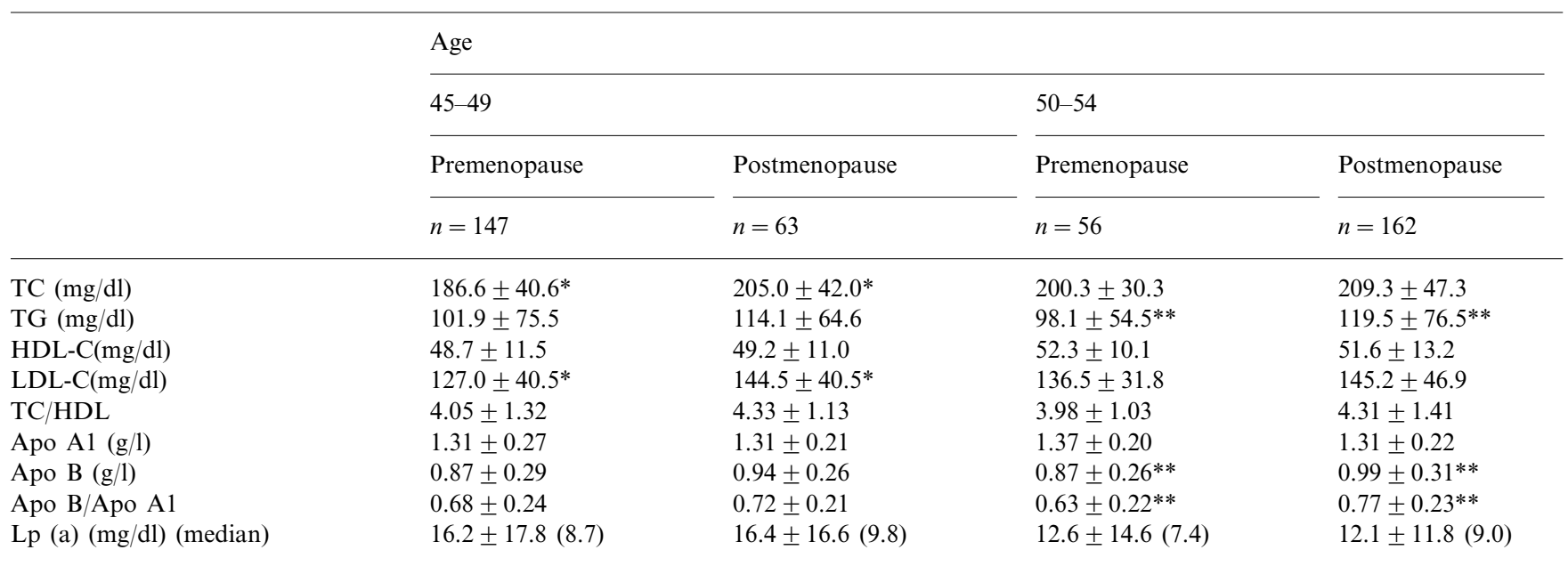

a Data are expressed as the mean \pm standard deviation (and median values for $\mathrm{Lp}(\mathrm{a})$ ).

$* P<0.01$ ( $t$-test).

** $P<0.05$ ( $t$-test).
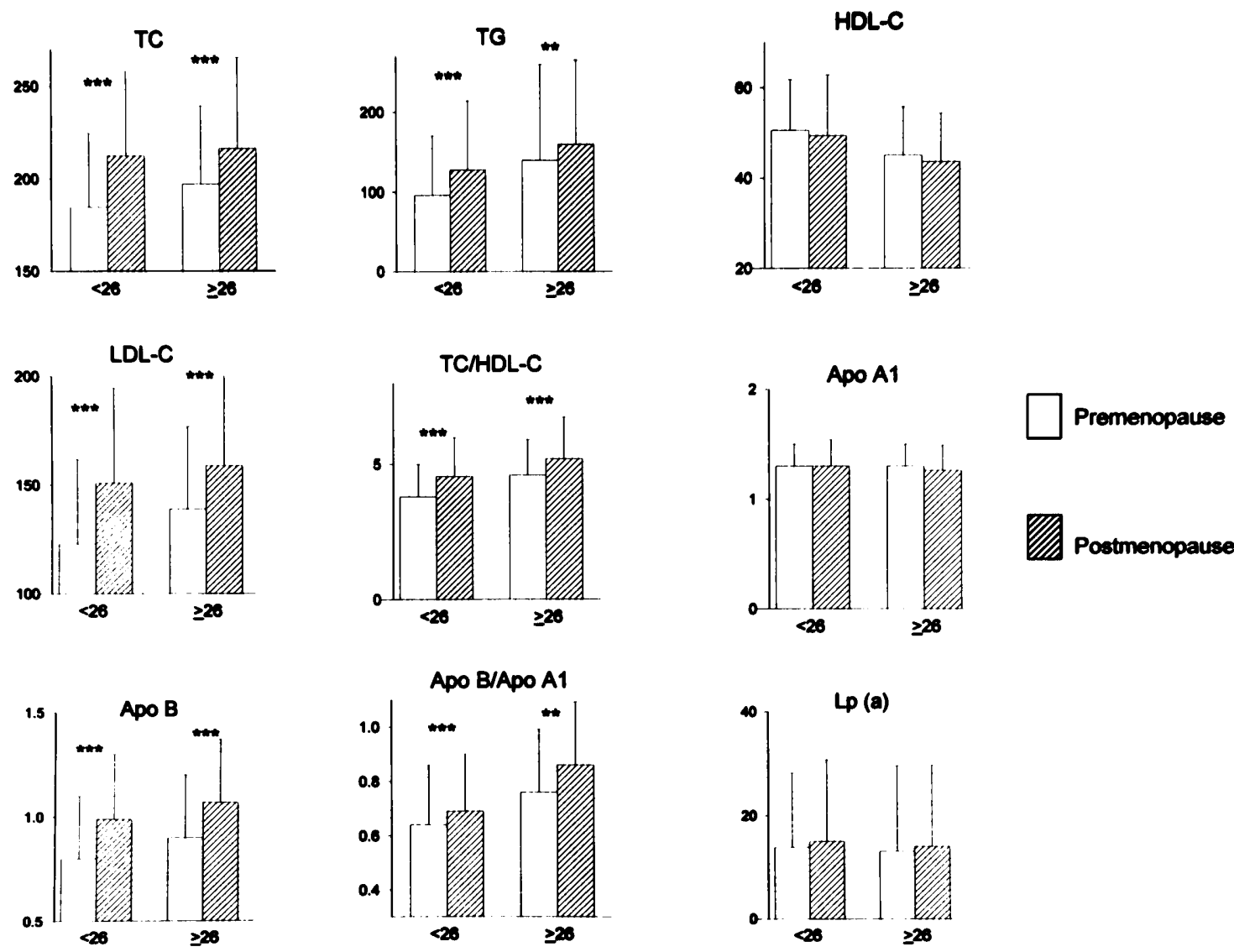

Fig. 2. Serum concentrations of lipids $\left(\mathrm{mg} / \mathrm{dl}\right.$, and $\mathrm{g} / \mathrm{l}$ for apoproteins) by menopausal status and obesity (body mass index $(\mathrm{BMI})<26 \mathrm{~kg} / \mathrm{m}^{2}$ : non-obese; BMI $\geq 26 \mathrm{~kg} / \mathrm{m}^{2}$ : obese) in women in Chin-Shan Community, Taiwan. ${ }^{* *}, P<0.01$; ${ }^{* *}, P<0.001$ (obese vs non-obese groups, $t$-test). 

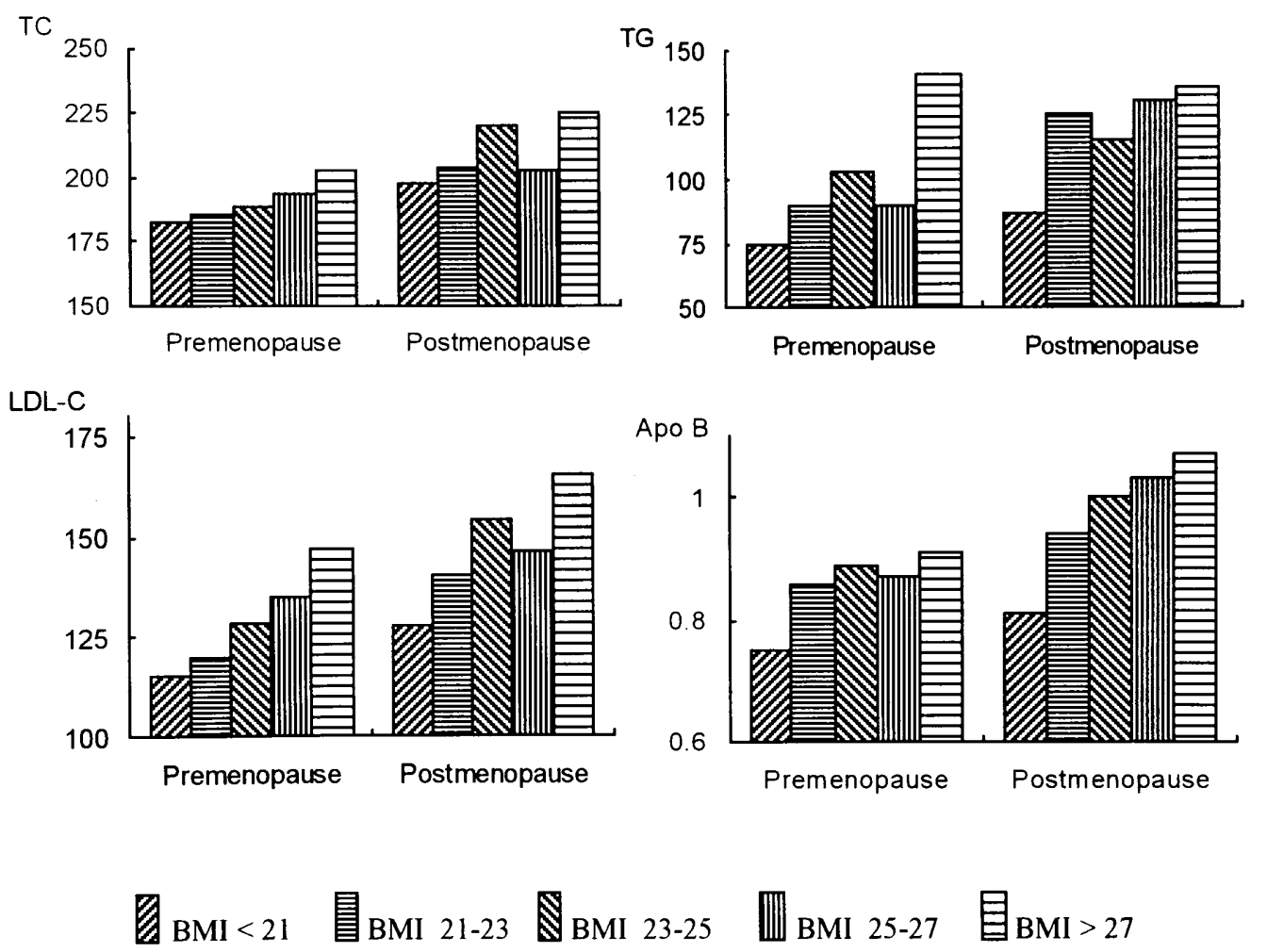

Fig. 3. Serum concentrations of lipids ( $\mathrm{mg} / \mathrm{dl}$, and $\mathrm{g} / 1$ for apoproteins) by body mass index (BMI) category $(<21,21-23,23-25,25-27$, and $\geq 27 \mathrm{~kg} / \mathrm{m}^{2}$ ) in premenopausal and postmenopausal women $45-54$ years of age in Chin-Shan Community, Taiwan. There were 25, 55, 54, 40, and 37 premenopausal women and 39,57, 50,36, and 35 postmenopausal women in the respective BMI categories.

\section{Discussion}

\subsection{Lipid profiles in premenopausal and postmenopausal women}

Lyu et al. [8] reported female age-adjusted CHD mortality was two-fold higher in the Framingham than in the Taipei population [8]. He attributed this difference to lower LDL-C and higher HDL-C levels in Taipei women. We found the population in Chin-Shan had a CHD mortality rate similar to that of women in Taipei, but had higher TG and LDL-C levels, and lower HDL-C levels, than pre- and postmenopausal women in both Taipei and Framingham. While Framingham women had the highest TC concentrations and Chin-Shan women the lowest, Taipei women had the highest HDL-C levels and Chin-Shan women the lowest. Compared with Chin-Shan women, both Taipei and Framingham women were younger, with $2 / 3$ of these women in the premenopausal state, these women accounted for only $44 \%$ of the current study population.

The levels of TC, LDL-C, HDL-C, Apo A1, Apo B, and $\mathrm{Lp}$ (a) were significantly higher in postmenopausal than in premenopausal women in Taipei, while only TC, TG, LDL-C, and Apo B levels were higher in postmenopausal women the in Framingham study. Sev- eral studies [5-10] reported changes in lipid profiles after menopause similar to those of the Chin-Shan women. However, a decrease in serum HDL-C levels after menopause was not seen in this study. This result may be controversial because the subclasses of HDL-C [26], which may be individually associated with menopause [7] not measured in our study.

Table 3

Regression coefficients (Pearson's $r$ ) for associations of lipid concentrations with age and BMI $\left(\mathrm{kg} / \mathrm{m}^{2}\right)$ by menopausal status for women in Chin-Shan Community Cardiovascular Cohort Study

\begin{tabular}{|c|c|c|c|c|}
\hline & \multicolumn{2}{|c|}{ Premenopause } & \multicolumn{2}{|c|}{ Postmenopause } \\
\hline & Age & BMI & Age & BMI \\
\hline $\mathrm{TC}(\mathrm{mg} / \mathrm{dl})$ & $0.70^{*}$ & $2.10 * *$ & 0.08 & 0.27 \\
\hline $\mathrm{TG}(\mathrm{mg} / \mathrm{dl})$ & 0.74 & $6.46^{* *}$ & 0.52 & $5.00 * *$ \\
\hline HDL-C (mg/dl) & 0.01 & $-0.85^{* *}$ & $-0.11^{*}$ & $-1.01 * *$ \\
\hline LDL-C (mg/dl) & $0.67^{*}$ & $2.76^{* *}$ & 0.13 & 0.88 \\
\hline TC/HDL-C & 0.02 & $0.12 * *$ & 0.01 & $0.10 * *$ \\
\hline Apo A1 (g/l) & 0.0009 & -0.006 & -0.002 & $-0.009 * * *$ \\
\hline Apo B (g/l) & 0.003 & $0.02 * *$ & 0.001 & $0.01 * *$ \\
\hline Apo B/Apo A1 & 0.004 & $0.04 * *$ & $0.004 *$ & $0.03 * *$ \\
\hline $\mathrm{Lp}$ (a) $(\mathrm{mg} / \mathrm{dl})$ & -0.02 & 0.14 & 0.09 & -0.24 \\
\hline
\end{tabular}

\footnotetext{
$* P<0.05$.

$* * \mathrm{P}<0.001$.

$* * * \mathrm{P}<0.01$.
} 
According to the classification of major risk factors for CHD defined by the National Cholesterol Education Program [27], postmenopausal women in Chin-Shan were at a higher risk for CHD than premenopausal women. Compared with the Framingham women, higher proportions of Chin-Shan women had LDL-C levels above $130 \mathrm{mg} / \mathrm{dl}$ and HDL-C levels below 35 $\mathrm{mg} / \mathrm{dl}$. LDL-C is a well-known risk factor for CHD [2]. The HDL-C level is universally related to CHD, although CHD is influenced by a variety of factors including biological, environmental, and behavioral characteristics [28]. Thus, differences in the levels of LDL-C and HDL-C between the Chin-Shan and Framingham cohorts cannot explain the lower rate of $\mathrm{CHD}$ mortality in the Chin-Shan study group. However, the average BMI of Framingham women was higher than that of Chin-Shan women [8]. It may be of interest to note that, due to religious beliefs, traditional families in Chin-Shan may consume more frequently a Taiwanese vegetarian diet. These meals consist mainly of soybean products, which have been claimed as the phyto-oestrogens products that may improve menopausal syndrome and prevent atherosclerosis [29]. It has been found the consumption of soybean may decrease plasma TC and LDL-C levels [30], though the other study found no alteration in plasma lipids in menopausal and perimenopausal women [31]. In addition, fish is also a primary protein source in Chin-Shan families as a fishing village is near by. Women in this study cohort are also active in their daily routines.

\subsection{Effect of age on lipid changes in the perimenopausal period}

The present study revealed changes in lipid profiles in menopausal women are age- associated. The TC and LDL-C levels were significantly higher in postmenopausal women aged 45-49 years than in premenopausal women in the same age group, as were the levels of TG and Apo B among women aged 50-54 years. Because no significant HDL-C change was observed in menopausal women, the TC change reflects the LDL-C change. This age- associated increase in TC and in LDL-C appeared to be significant only in premenopausal women, i.e. once the LDL-C level increases in response to menopause, the age association with LDL-C became less apparent. Other cross-sectional and longitudinal studies have examined similar patterns of TC, TG, and LDL-C levels in menopausal women. Both TC and LDL-C levels may be remarkably elevated from 1 to 2 years before menopause [10,32] to years after menopause [32,33]. Serum TG levels can show a similar pattern of increase before menopause [10]. The LDL-C level was reported to rise substantially with age in women $<53$ years old [6]. In CCCC study, the association between LDL-C concentration with menopause was greatest if menopause occurred between the ages of 45 and 49 years.

Recent studies have debated the association between obesity, age and lipids and circulating estrogen levels [34-36]. The change in estrogen levels has a significant effect on the redistribution of lipids [37]. The estrogen levels are unknown for the women in this study.

\subsection{The effect of obesity on lipid changes}

Obesity in women has been found to be strongly associated with elevated levels of TC, LDL-C, $[18,38]$ and TG, and lowered HDL-C [18,36,38], even after controlling for age [38] and estrogen levels [36]. This correlation is strongest in women $35-54$ years of age [18]. In this study, we found significant associations between BMI and TC, LDL-C, TG, HDL-C, Apo B levels. This correlation was independent of age, and the rising trend was closely associated with the increase in BMI. This trend was even more obvious at the ages of perimenopausal. A substantial decrease in Apo A1 concentration with decreasing estrogen levels after menopause also has been reported [5,39]. However, we found our Apo A1 levels to be highest in the 50-54 years bands, contrary to the reported declining estrogen levels before [10,40] and after [41] menopause. We also found that after menopause Apo A1 concentration was negatively related to BMI; this has not been reported elsewhere.

Reeder et al. [18] reported that TG and HDL-C levels are most strongly associated with abdominal obesity, and the least strongly associated with LDL-C and TC. They did not consider the effect of menopause. In our study, the associations between BMI and both TC and LDL-C were stronger before than after menopause. This suggests menopause also affects LDL-C and TC rather than obesity itself. Menopausal changes are less dramatic in obese women for TC, TG and LDL-C, but not for Apo B, TC/HDL-C or HDL-C (Fig. 2).

Body fat shifts from the subcutaneous to the intra-abdominal area during menopause, and results in an android-type fat distribution [42,43]. Women with android-type obesity show less favorable lipid and lipoprotein profiles than those with gynoid-type obesity [44]. BMI has long been claimed to be a simple, precise predictor for assessing the risk of abdominal obesity [18]. Obesity itself presents a rather complex metabolic status. Obesity in women is associated with insulin resistance and an altered lipoprotein composition [45]. In our study, the change in lipid profiles (in TC, TG, and LDL-C) after menopause was slightly less dramatic in obese than in non-obese women. No BMI change was seen in Chin-Shan women after menopause. This may suggest that metabolic characteristics causing dyslipidemia in obese subjects are more important than the occurrence of menopause. 


\subsection{Unique feature of $\mathrm{Lp}(\mathrm{a})$ in perimenopausal women}

Previous studies generally showed small changes in Lp (a) levels in postmenopausal women $[2,46,47]$. Our data also demonstrated no changes in $\mathrm{Lp}$ (a) when overall average values between premenopausal and postmenopausal women were compared, regardless of whether BMI was considered; although, postmenopausal women had a higher median value of $\mathrm{Lp}$ (a). We also found Levels of LDL-C, TG and HDL-C corresponded to Lp (a) levels [48]. Serum Lp (a) level has been reported to increase gradually with age in women [6], especially those aged $44-58$ years [49]. In this study, the distribution of $\mathrm{Lp}$ (a) showed a peak at 45-49 years and did not climb again until after menopause at 55-59 years old. We believe that this unique pattern of Lp levels in Chin-Shan women is influenced by both age and menopause and has no relationship with BMI.

\subsection{Conclusions}

The changes in lipid profiles after menopause, particularly apoprotein levels, are more complicated for obese women than for non-obese women, and are probably multifactorial in origin. However, this study demonstrated the obvious influence of obesity on TC, LDL-C, TG, and Apo B levels in middle age Chin-Shan women who were experiencing menopause. It is not necessary that serum lipid levels have stronger association with menopause and BMI than with age.

\section{Acknowledgements}

This work was supported by grants (DOH-79-06 and DOH-80-30) from the Department of Health, Republic of China. We thank Dr Chu-Hsing Hsiao for statistical consultation.

\section{References}

[1] Kannel WB, Wilson PWF. Risk factors that attenuate the female coronary disease advantage. Arch Intern Med 1995;155:57-61.

[2] Kannel WB. Metabolic risk factors for coronary heart disease in women: perspective from the Framingham study. Am Heart $\mathbf{J}$ 1987;114:413-9.

[3] Manhem K. Cardiovascular risk of postmenopausal women: what is known and what is unknown. In: Safar M, Stimpel M, Zanchetti A, editors. Hypertension in Menopausal Women. Berlin: Springer-Verlag, 1994:3-13.

[4] Casiglia E, d'Este D, Ginocchio G, Colangeli G, Onesto C, Tramontin $\mathrm{P}$, et al. Lack of influence of menopause on blood pressure and cardiovascular risk profile: a 16-year longitudinal study concerning a cohort of 568 women. J Hypertens $1996 ; 14: 729-36$
[5] Campos H, McNamara JR, Wilson PWF, Ordovas JM, Schaefer EJ. Differences in low density lipoprotein subfractions and apolipoproteins in premenopausal and postmenopausal women. J Clin Endocrinol Metab 1988;67:30-5.

[6] Brown SA, Hutchinson R, Morrisett J, Boerwinkle E, Davis CE, Gotto AM, et al. Plasma lipid, lipoprotein cholesterol and apoprotein distributions in selected US communities: the atherosclerosis risk in communities (ARIC) study. Arterioscler Thromb 1993; 13:1139-58.

[7] Stevenson JC, Crook D, Godsland IF. Influence of age and menopause and serum lipid and lipoproteins in healthy women. Atherosclerosis 1993;98:83-90.

[8] Lyu LC, Shieh MJ, Ordovas JM, Lichtenstein AH, Wilson PW, Schaefer EJ. Plasma lipoprotein and apolipoprotein level in Taipei and Framingham. Arterioscler Thromb 1993;13:1429-40.

[9] Matthews KA, Meilahn E, Kuller LH, Kelsey SF, Caggiula AW, Wing RR. Menopause and risk factors for coronary heart disease. New Engl J Med 1989;321:641-6.

[10] Ushiroyama T, Okamoto Y, Sugimoto O. Plasma lipid and lipoprotein levels in perimenopausal women. Acta Obstet Gynecol Scand 1993;72:428-33.

[11] Weijenberg MP, Feskens EJM, Bowles CH, Kromhout D. Serum total cholesterol and systolic blood pressure as risk factors for mortality from ischemic heart disease among elderly men and women. J Clin Epidemiol 1994;47:197-205.

[12] Gordon DJ, Probstfield JL, Garrison RJ, Neaton JD, Castelli WP, Knoke JD, et al. High density lipoprotein cholesterol and cardiovascular disease: four prospective American studies. Circulation 1989;79:8-15.

[13] Schwandt P. The triglyceride controversy: a review of the data. Eur Heart J 1990;11:38-43.

[14] Solymoss BC, Marcil M, Wesolowska E, Gilfix BM, Lesperance J, Campeau L. Relation of coronary artery disease in women $<60$ years of age to the combined elevation of serum lipoprotein (a) and total cholesterol to high density cholesterol ratio. Am J Cardiol 1993;72:1215-9.

[15] Hubert HB, Feinleib M, McNamara PM, Castelli WP. Obesity as an independent risk factor for cardiovascular disease: a 26year follow-up of participants in the Framingham heart study. Circulation 1983;67:968-77.

[16] Manson JE, Colditz GA, Stampfer MJ, Willett WC, Rosner B, Manson RR, et al. A prospective study of obesity and risk of coronary heart disease in women. New Engl J Med 1990;322:882-9.

[17] Despres JP, Moorjani S, Ferland M, Tremblay A, Lupien PJ, Nadeau A, et al. Adipose tissue distribution and plasma lipoprotein levels in obese women: importance of intra-abdominal fat. Arteriosclerosis 1989;9:203-10.

[18] Reeder BA, Senthilselvan A, Despr(s JP, Angel A, Liu L, Wang $\mathrm{H}$, Rabkin SW. The association of cardiovascular disease risk factors with abdominal obesity in Canada. CMAJ 1997;157:S39-45.

[19] Chow SN, Huang CC, Lee YT. Demographic characteristics and medical aspects of menopausal women in Taiwan. J Formos Med Assoc 1997;96:806-11.

[20] Health and Vital Statistics, 1995. Department of Health. Executive Yuan, Republic of China. Taipei, Taiwan. 1995:134-147.

[21] Chung MY, Jeng JS, Yip PK, Hwang BS, Chang YC. Study on blood lipids, lipoproteins and apolipoproteins in different types of ischemic stroke. Acta Neurol Sin 1994;3:194-9.

[22] Chien KL, Lee YT, Sung FC, Hsu HC, Su TC, Lin RS. Hyperinsulinemia and related atherosclerotic risk factors in the population at cardiovascular risk: a community-based study. Clin Chem 1999;45:938-46.

[23] Wieland H, Seidel D. A simple specific method for precipitation of low density lipoproteins. J Lipid Res 1983;24:904-9. 
[24] Enzi G, Gasparo M, Biondetti PR, Fiore D, Semisa M, Zurlo F. Subcutaneous and visceral fat distribution according to sex, age and overweight, evaluated by computed tomography. Am J Clin Nutr 1986;44:739-46.

[25] Huang PC, Yu SL, Lin YM, Chu CL. Body weight in Chinese adults by sex, age and body height and criterion of obesity based on body mass index. J Chinese Ntur Soc 1992;17:157-72.

[26] Williams PT, Vranizan KM, Austin MA, Krauss RM. Associations of age, adiposity, alcohol intake, menstrual status, and estrogen therapy with high-density lipoprotein subclasses. Arterioscler Thromb 1993;13:1654-61.

[27] The Expert Panel. Report of the National Cholesterol Education Expert Panel on Detection, Evaluation and Treatment of High Blood Cholesterol in Adults. Arch Intern Med 1988;148:36-69.

[28] De Backer G, de Bacquer D, Kornitzer M. Epidemiological aspects of high density lipoprotein cholesterol. Atherosclerosis 1998;137:S1-6.

[29] Aldercreutz H, Mazur W. Phyto-oestrogens and western diseases. Ann Med 1997;29:95-120.

[30] Washburn S, Burke GL, Morgan T, Anthony M. Effect of soy protein supplementation on serum lipoproteins, blood pressure, and menopausal symptoms in perimenopausal women. Menopause 1999;6:7-13.

[31] Nestel PJ, Yamashita T, Sasahara T, Pomeroy S, Dart A, Komesaroff $\mathrm{P}$, et al. Soy isoflavones improve systemic arterial compliance but not plasma lipids in menopausal and perimenopausal women. Arterioscler Thromb Vas Biol 1997;17:3392-8.

[32] Akahoshi M, Soda M, Nakashima E, Shimaoka K, Seto S, Yano $\mathrm{K}$. Effects of menopause on trends of serum cholesterol, blood pressure, and body mass index. Circulation 1996;94:61-6.

[33] Van Beresteijn ECH, Korevaar JC, Huijbregts PCW, Schouten EG, Burema J, Kok FJ. Perimenopausal increase in serum cholesterol: a 10-year longitudinal study. Am J Epidemiol 1993;137:383-92.

[34] Pasquali R, Casimirri F, Pascal G, Tortelli O, Morselli, Labate A, Bertazzo D, et al. Influence of menopause on blood cholesterol levels in women: the role of body composition, fat distribution and hormonal milieu, Virgilio Menopause Health Group. J Int Med 1997;241:195-203.

[35] Longcope C, Herbert PN, McKinlay SM, Goldfield SR. The relationship of total and free estrogens and sex hormone-binding globulin with lipoproteins in women. J Clin Endocrinol Metab 1990;71:67-72.

[36] Cauley JA, Gutai JP, Kuller LH, Powell JG. The relation of endogenous sex steroid hormone concentrations to serum lipid and lipoprotein levels in postmenopausal women. Am J Epidemiol 1990;132:884-94.

[37] Bjorntorp P. The regulation of adipose tissue distribution in humans. Int J Obes Relat Metab Disord 1996;20:291-302.

[38] Heitmann BL. The effects of gender and age on associations between blood lipid levels and obesity in Danish men and women aged 35-65 years. J Clin Epidemiol 1992;45:693-702.

[39] Kuller LH, Gutai JP, Meilahn E, Matthews KA, Plantinga P. Relationship of endogenous sex steroid hormones to lipids and apoproteins in postmenopausal women. Arteriosclerosis 1990;10:1058-66.

[40] Sherman BM, West JH, Korenman SG. The menopausal transition: analysis of LH, FSH, estradiol, and progesterone concentrations during menstrual cycles of order women. J Clin Endocrinol Metab 1976;42:629-36.

[41] Chakravarti S, Collins WP, Forecast JD, Newton JR, Oram $\mathrm{DH}$, Studd JW. Hormone profiles after the menopause. Br Med J 1976;2:784-7.

[42] Ley CJ, Lees B, Stevenson JC. Sex- and menopause- associated changes in body fat distribution. Am J Clin Nutr 1992;55:950-4.

[43] Bjorkelund C, Lissner L, Andersson S, Lapidus L, Bengtsson C. Reproductive history in relation to relative weight and fat distribution. Int J Obes Relat Metab Disord 1996;20:213-9.

[44] Van Gaal L, Vansant G, Van Campenhout C, Lepoutre L, De Leeuw I. Apolipoprotein concentrations in obese subjects with upper and lower body fat mass distribution. Int $\mathbf{J}$ Obes Relat Metab Disord 1989;13:255-63.

[45] Winocour PH, Kaluvya S, Ramaiya K, Brown L, Millar JP, Farrer M, et al. Relation between insulinemia, body mass index, and lipoprotein composition in healthy, nondiabetic men and women. Arterioscler Thromb 1992;12:393-402.

[46] De Pergola GD, Giorgino F, Cospite MR, Giagulli VA, Cignarelli M, Ferri G, et al. Relation between sex hormones and serum lipoprotein and lipoprotein (a) concentrations in premenopausal obese women. Arterioscler Thromb 1993;13:675-9.

[47] Nago N, Kayaba K, Hiraoka J, Matsuo H, Goto T, Kario K, et al. Lipoprotein (a) levels in the Japanese population: influence of age and sex, and relation to atherosclerotic risk factors. Am J Epidemiol 1995;141:815-21.

[48] Chien KL, Lee YT, Sung FC, Su TC, Hsu HC, Lin RS. Lipoprotein (a) level in the population in Taiwan: relationship to sociodemographic and atherosclerotic risk factors. Atheriosclerosis 1999;143:267-73.

[49] Bottiglioni F, de Aloysio D, Nicoletti G, Mauloni M, Mantuano M, Motta R. Physio-pathological aspects of body weight in the female climacteric. Maturitas 1984;5:153-69. 